\title{
Investigating the stability of Second Phase Particles in Zr-Nb alloys under irradiation
}

Guanze $\mathrm{He}^{1}$, Junliang $\mathrm{Liu}^{1}$, Kexue $\mathrm{Li}^{1}$, Jing $\mathrm{Hu}^{2}$, Anamul Haq Mir ${ }^{3}$, Sergio LozanoPerez $^{1}$, Chris Grovenor ${ }^{1}$

1. Department of Materials, University of Oxford, Parks Road, Oxford, UK, OX1 3PH

2. Argonne National Laboratory, 9700 S. Cass Avenue, Argonne, IL, 60439, United States

3. School of Computing and Engineering, University of Huddersfield, Queensgate, Huddersfield HD1 3DH, UK

\begin{abstract}
The stability of the $\beta$-Nb Second Phase Particles (SPPs) in two types of Zr-Nb alloys (recrystallised $\mathrm{Zr}-1.0 \mathrm{Nb}$ and $\mathrm{Zr}-2.5 \mathrm{Nb}$ ) was studied by in-situ heavy ion irradiation in a transmission electron microscope (TEM), combined with ex-situ analysis by energy dispersive $\mathrm{x}$-ray spectroscopy (EDX). TEM thin foils were irradiated by $1 \mathrm{MeV} \mathrm{Kr}^{+}$ ions at four different temperatures from $50 \mathrm{~K}$ to $873 \mathrm{~K}$, and by $350 \mathrm{keV} \mathrm{Kr}{ }^{+}$ions at different doses up to 39dpa. The change in size of individual $\beta$-Nb SPPs has been measured quantitatively, and the degradation mechanisms under irradiation at different temperatures discussed. It has been shown that the Nb redistribution between the SPPs and the Zr matrix is governed both by radiation induced mixing and local diffusion in the surrounding Zr matrix. Under the radiation conditions reported in this study, the $\beta$-Nb SPPs have shown remarkably stability against irradiation, and the extent of $\mathrm{Nb}$ redistribution between the SPPs and $\mathrm{Zr}$ matrix is very limited under all experimental conditions.
\end{abstract}

\section{Keywords}

second phase particles, zirconium, $\beta$-Nb, in-situ heavy ion irradiation, Zr-Nb alloy, STEM EDX 


\section{Introduction}

Zirconium alloys have widely been used as the fuel cladding materials in watercooled nuclear reactors over the past several decades. To achieve better economic and safety performance, higher burn-up fuel designs are required by the industry [1], and hence the design of new zirconium alloys with longer operating lifetimes in the core. As well as factors such as pellet-cladding interactions, hydriding and irradiationinduced creep, water facing corrosion has been long regarded as one of the major lifelimiting factors [2]. This oxidation process commonly consists of pre-transition and transition cycles [3], and while the oxide film grows slowly in the pre-transition regime, obeying 'parabolic' or 'sub-parabolic' growth rate laws [4][5], 'break-away' growth occurs in the transition regime with much higher oxidation rates [3]. The onset of the detrimental 'break-away' phenomenon of accelerated oxide film growth has been shown to be related to micro-structural and micro-chemical properties of the metal and oxide [6], including the choice of major alloying elements like $\mathrm{Nb}$ or $\mathrm{Sn}$ [7][8][9] and the size and chemistry of second phase particles (SPPs) [10]. Under inreactor conditions, the harsh working environment can also affect the corrosion resistance. Comparison between autoclave corroded and ex-reactor samples shows that neutron irradiation significantly accelerates the oxidation process in Sncontaining alloys [11][12]. It is thus of interest to study the interplay of different mechanisms controlling the phenomenon of radiation-enhanced corrosion.

Several types of SPPs are found in the zirconium alloys used for fuel cladding applications since the content of both deliberately added and trace impurity alloying elements usually far exceeds the solubility limit. It has been shown that many different metallurgical aspects of the SPPs can influence the oxidation performance. For instance, Bojinov et al. reported that a slower oxidation rate in Zircaloy-2 alloys in the pre-transition stage could be correlated to small SPPs [13], yet Tejland et al. showed over longer oxidation periods covering the kinetic transition that a smaller average size of SPPs could lead to a higher oxidation rate in similar Zircaloy-2 
materials [10]. A similar conclusion was drawn from experiments on Zircaloy-4 which showed that larger SPPs (150 nm) were beneficial for the corrosion resistance [14]. The type of SPP also plays an important role in determining the distribution of alloying elements remaining in solid solution, which since it is the metal matrix that corrodes has been the parameter increasingly used to explain the effect of chemistry changes on the overall oxidation rate [15][16].

Because the SPPs contain much of the total content of alloying elements, studying the effect of radiation damage on the release of these elements to the metallic matrix is of great importance to help understand the in-reactor acceleration of oxidation. Zr-Nb alloys have been shown to have a better in-core corrosion resistance [17], and so have been especially well studied. The majority of the SPPs in these alloys are $\beta-\mathrm{Nb}$, and the behaviour of this phase under irradiation is of particular interest. Irradiationinduced coarsening of the $\beta$-Nb SPPs, and a concurrent reduction in matrix $\mathrm{Nb}$ content, has been reported in ex-reactor samples of several Zr-Nb alloys [18] [19] [20]. The key changes include an increase in average SPP size from $50 \mathrm{~nm}$ to $80 \mathrm{~nm}$ after $20 \mathrm{dpa}$ at $600 \mathrm{~K}$ [21] and from $35 \mathrm{~nm}$ to $50 \mathrm{~nm}$ after 5 dpa under service conditions [19]. At the same time the reduction of $\mathrm{Nb}$ content in the SPPs from 80 wt $\%$ to around $55 \mathrm{wt} \%$ has been reported [19], and the retention of the bcc structure [22]. As suggested by Shishov et al [20] and Kobylyansky et al [18], the mechanism for this composition change is that $\mathrm{Nb}$ atoms are displaced from the SPPs by $\mathrm{Zr}$ atoms themselves displaced from collision cascades in the surrounding matrix. These analyses are based on comparisons of the average size of $\beta$-Nb SPPs in initial and irradiated materials rather than the direct observation of the effect of irradiation on individual SPPs.

In this work, Zr-Nb alloys have been irradiated in-situ by heavy ions at different temperatures and to different damage levels. The same SPPs were tracked before and after irradiation to provide a direct evidence of the changes happened to individual SPPs under irradiation. Microstructural and local chemical changes were studied by 
TEM diffraction and STEM EDX analysis to help better understand the behaviour of these SPPs under irradiation.

\section{Experimental Details}

\subsection{Materials and sample preparation}

The materials used in this series of experiments are recrystallised (RXA) Zr-1.0Nb and $\mathrm{Zr}-2.5 \mathrm{Nb}$ alloys provided by Westinghouse ${ }^{\mathrm{TM}}$. The final heat treatment at $560{ }^{\circ} \mathrm{C}$ created equiaxed $\beta$-Nb and Zr-Nb-Fe phase SPPs in a polycrystalline $\alpha$-Zr matrix. Our focus here has been on the $\beta-\mathrm{Nb}$ SPPs, which have an initial radius of about $40 \mathrm{~nm}$, and the average grain size in the $\alpha$-Zr matrix is about $2 \mu \mathrm{m}$. The composition of these two alloys was measured by Inductively Coupled Plasma Mass Spectrometry (ICPMS), and the main elements are given in Table 1.

Table 1 Composition of Zr-1.0Nb and Zr-2.5Nb alloys

\begin{tabular}{|c|c|c|c|c|}
\hline Material & $\mathrm{Nb}(w t \%)$ & Fe (wtppm) & $\mathrm{H}$ (wtppm) & $\mathrm{Zr}$ \\
\hline $\mathrm{Zr}-1 \mathrm{Nb}$ & 1 & 753 & 13 & balance \\
\hline $\mathrm{Zr}-2.5 \mathrm{Nb}$ & 2.5 & 440 & - & balance \\
\hline
\end{tabular}

All TEM samples were prepared by focused ion beam (FIB) milling using the in-situ lift-out method [23]. An FEI 200 FIB fitted with a static in-situ micromanipulator was used to deposit a protective Pt layer on mechanically polished samples, and lamellas prepared of about $15 \mu \mathrm{m} \times 10 \mu \mathrm{m} \times 1.5 \mu \mathrm{m}$. A ZEISS NVision 40 dual beam FIB was used to further thin the lamellas down to about a thickness of $\sim 150 \mathrm{~nm}$ using a $30 \mathrm{kV}$ $\mathrm{Ga}^{+}$beam with current gradually decreased from 700-80 pA. A low energy surface cleaning step was also applied using a $5 \mathrm{kV} 250 \mathrm{pA} \mathrm{Ga}^{+}$beam to further thin the lamellas down to about $100 \mathrm{~nm}$ and reduce the extent of surface FIB damage [24].

A JEOL 3000F (300 kV, FEG source) was used for TEM and STEM Energy

Dispersive X-Ray Spectroscopy (EDX) observations before and after irradiation. The facility is equipped with an Oxford Instrument X-MAX EDX detector and Aztec 
analysis system. Electron energy loss (EELS) measurements [23] were used to determine the thickness of the TEM samples [25] prior to irradiation using a JEOL ARM200F microscope (200 kV, CFEG source, Cs probe corrected).

\subsection{In-situ irradiations at IVEM and MIAMI2}

The first set of in-situ irradiation experiments was carried out at the Intermediate Voltage Electron Microscopy (IVEM)-Tandem Facility at Argonne National Laboratory. A Hitachi-9000 microscope (300 kV, LaB6 source) was used for TEM observations, with in-situ irradiation realised by the intersection of the accelerated ion beam and electron beam at the sample stage in the TEM column. $1 \mathrm{MeV} \mathrm{Kr}^{2+}$ ions at a flux of $8 \times 10^{11} \mathrm{~cm}^{-2} \mathrm{~s}^{-1}$ were used to irradiate RXA Zr-2.5Nb at $50 \mathrm{~K}, 293 \mathrm{~K}, 623 \mathrm{~K}$ and $873 \mathrm{~K}$. The accumulated fluence was $1.2 \times 10^{16} \mathrm{~cm}^{-2}$ at $50 \mathrm{~K}, 1.28 \times 10^{16} \mathrm{~cm}^{-2}$ at $293 \mathrm{~K}$, $1.6 \times 10^{16} \mathrm{~cm}^{-2}$ at $623 \mathrm{~K}$ and $873 \mathrm{~K}$. According to SRIM simulation using the KinchinPease damage calculation model [26], this corresponds to an irradiation dose rate of $0.0015 \mathrm{dpa} / \mathrm{s}$, and a total damage level of $15 \mathrm{dpa}$ at $50 \mathrm{~K}$, 16dpa at $293 \mathrm{~K}, 20 \mathrm{dpa}$ at $623 \mathrm{~K}$ and $873 \mathrm{~K}$. Bright field (BF) and Weak beam dark field (WBDF) images of the entire irradiation session were recorded using a Gatan OneView digital camera.

The second set of experiments was done at the MIAMI2 facility, University of Huddersfield, UK, using a Hitachi-9500 microscope (300 kV, LaB6 source). 350 keV $\mathrm{Kr}^{+}$ions were used to irradiate the $\mathrm{Zr}-1.0 \mathrm{Nb}$ samples at $623 \mathrm{~K}$. Four samples were irradiated to different total fluences at a flux of around $6 \times 10^{11} \mathrm{~cm}^{-2} \mathrm{~s}^{-1}$. Details of the irradiation parameters used at the IVEM and MIAMI2 facilities are presented in Table 2.

As discussed below, measuring any damage-induced thickness changes in the samples is crucial to interpreting the EDX measurements. To calibrate this effect, an additional experiment on MIAMI2 using $700 \mathrm{keV} \mathrm{Kr}^{+2}$ ions with similar parameters to those described above was carried out, and the sample thickness before and after irradiation measured by the $t / \lambda$ method in the EFTEM mode [25]. 
Table 2 Parameters used for IVEM and MIAMI2 irradiation

\begin{tabular}{|l|l|l|l|l|l|l|l|l|l|}
\hline Sample No. & $\mathbf{1}$ & $\mathbf{2}$ & $\mathbf{3}$ & $\mathbf{4}$ & $\mathbf{a}$ & $\mathbf{b}$ & $\mathbf{c}$ & $\mathbf{d}$ & $\mathbf{A}$ \\
\hline $\begin{array}{l}\text { Irradiation } \\
\text { Energy(keV) }\end{array}$ & 1000 & 1000 & 1000 & 1000 & 350 & 350 & 350 & 350 & 700 \\
\hline $\begin{array}{l}\text { Irradiation } \\
\text { temperature } \\
\text { (K) }\end{array}$ & 50 & 293 & 623 & 873 & 623 & 623 & 623 & 623 & 293 \\
\hline $\begin{array}{l}\text { dose rate } \\
(\mathbf{1 0}-\mathbf{d} \text { dpa/s) }\end{array}$ & 1.5 & 1.5 & 1.5 & 1.5 & 1.78 & 2.88 & 1.61 & 2.30 & 1.1 \\
\hline dose (dpa) & 16 & 15 & 20 & 20 & 6.4 & 10.4 & 20.2 & 38.8 & 10 \\
\hline
\end{tabular}

\subsection{EDX line-scans and non-linear curve fitting of line-scan profiles}

We have approached the problem of measuring any elemental redistribution from SPPs under irradiation by comparing the STEM EDX line-scan profiles of $\mathrm{Zr}$ and $\mathrm{Nb}$ from the same SPP before and after irradiation. For each SPP, two line profiles, perpendicular to each other and intersecting at the centre were acquired. The following measures were taken during EDX acquisition to ensure that the results could be interpreted quantitatively. First the instrument conditions were kept as identical as possible. This included the microscope always being operated at $300 \mathrm{kV}$, source emission current at the same level, use of the same low background double-tilt holder, using the same probe forming condenser apertures and the same camera length and magnification. Oxford Instrument's Aztec software was used to acquire and analyse all the EDX data, and all the line-scans were taken in 'true line' mode with the background subtracted. The EDX results are presented as raw counts because that makes the study of any out-diffusion phenomena more reliable than after quantification routines which can introduce artefacts as a result of the very different compositions of the matrix and SPP. The step size was fixed to $0.6 \mathrm{~nm}$ for all samples, 
and the dwell time to $10 \mathrm{~ms}$.

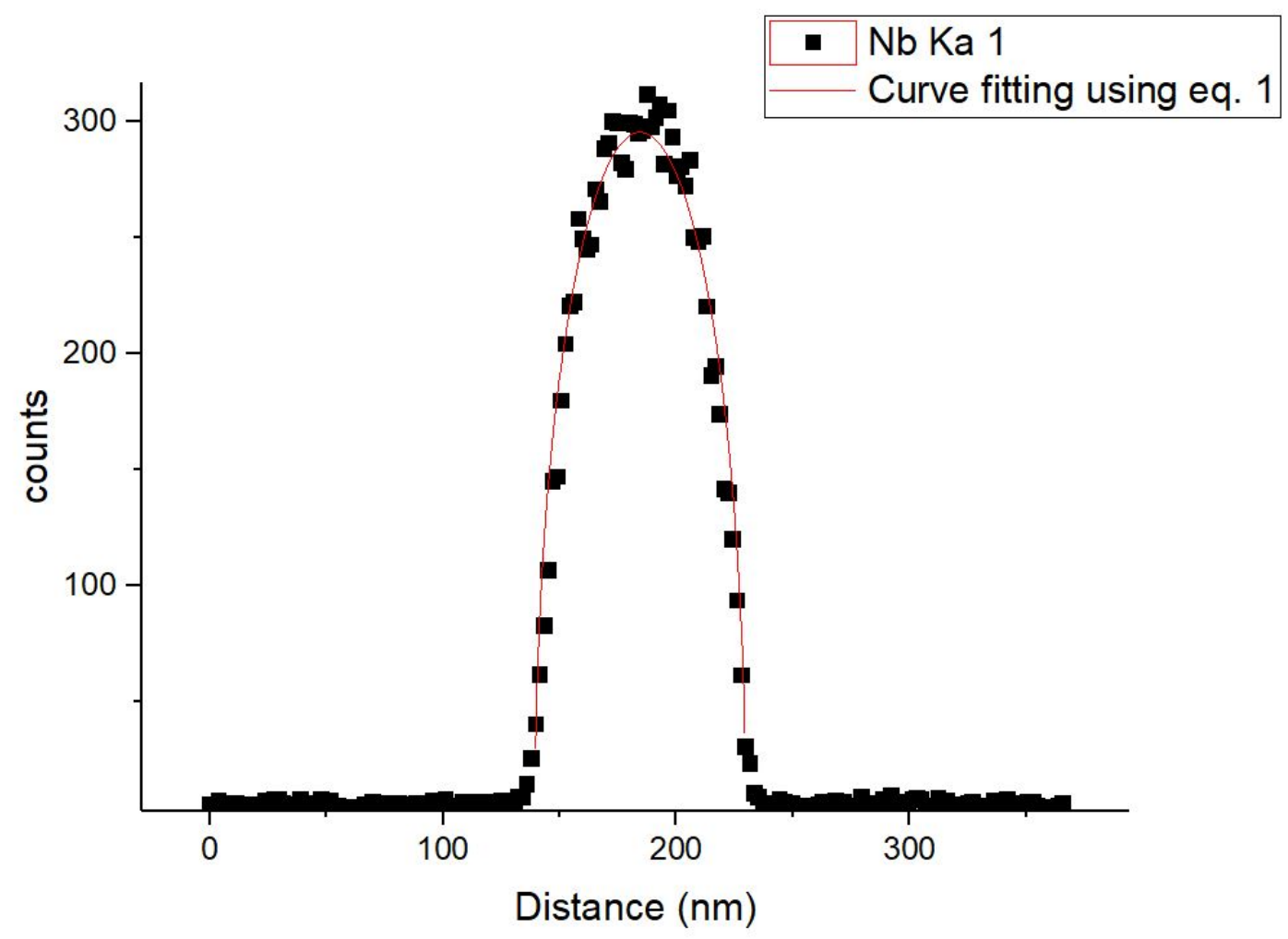

Figure 1 Typical Nb line-scan profile and the fitted curve of across a $\beta$-Nb SPP.

To compensate for the effect of irradiation-induced bending, which happened to all the samples during the in-situ experiments, they were always tilted back to the same

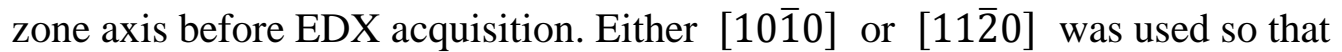
orthogonal line-scans could be carried out along the a- and c-directions of the hcp $\alpha$ Zr matrix. Taking EDX scans directly along a zone axis can result in channelling and a reduction in the reliability of the quantitative data [27], for this reason, we have only used qualitative line profile (counts) for the comparison between samples. In addition, the accumulated radiation damage (dislocations and point defects) could have an effect on the degree of channelling and make the comparison between samples unviable. For this reason, as shown in Appendix 1, the effect of channelling on EDX Zr signal was compared between unirradiated and irradiated samples. Our findings suggest that the effect of irradiation on channelling is negligible (within error), enabling the comparison of EDX lines-cans over selected SPP before and after 
irradiation.

A typical line-scan profile of $\mathrm{Nb}$ content in an SPP and the neighbouring matrix is shown in Figure 1. Quantitative analysis is needed to better understand the degree of elemental redistribution and the underlying damage mechanisms. By assuming that the SPPs are spherical in shape and fully embedded in the TEM foils, the corresponding SPP size along the line scan can be obtained by taking non-linear curve fitting of the line-scan profiles using:

$$
I=k \times \sqrt{R^{2}-\left(x-x_{0}\right)^{2}}+C
$$

where $\mathrm{k}$ is a scaling factor, $\mathrm{R}$ represents the measured radius of the SPP, $\mathrm{x}_{0}$ represents the position of the centre of the SPP, $\mathrm{C}$ is the background signal intensity outside the particle and I the signal intensity detected at a point $\mathrm{x}$ far from the centre. The background-subtracted intensity should become 0 when $x=R$, corresponding to the periphery of the SPP.
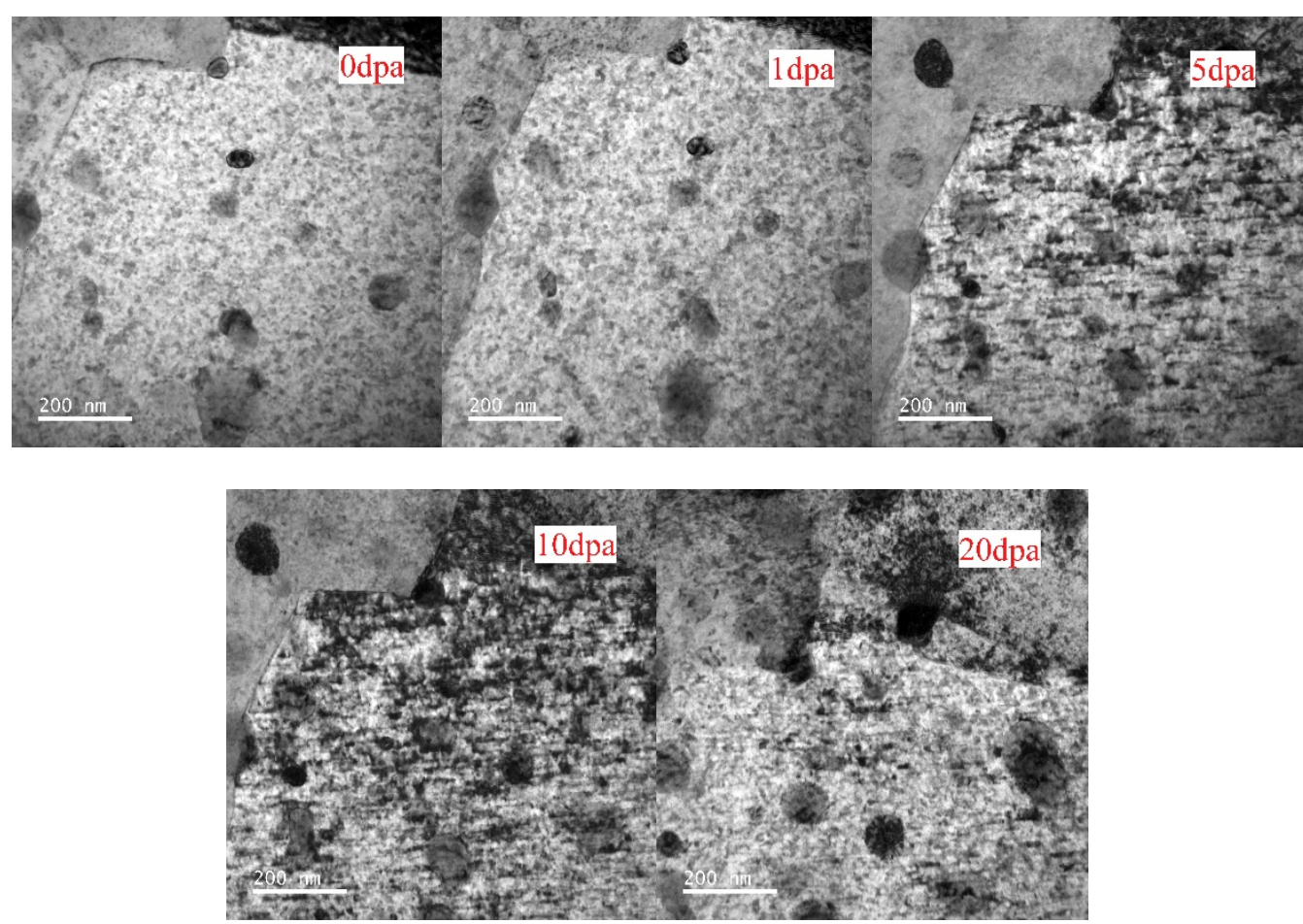

Figure 2 A series of TEM-BF images showing the same region in a sample irradiated by $1 \mathrm{MeV} \mathrm{Kr}$ ions to 20 dpa at $623 \mathrm{~K}$. Two beam condition with $g=[0002]$ was used for the BF images. The straight black lines in the right hand side grain starting appearing at 5 dpa are c-loops. 
TEM bright field images can also be used to identify and measure the size of SPPs, and might be considered more straightforward than the method described above. However, it can be difficult to identify the precise shape of SPPs when the images also contain other features like dislocations and surface oxides, and there are changes to the apparent size of SPPs as a result of sample bending. These effects are illustrated a set of typical images in Figure 2. As a result, EDX results are preferred here for accurate SPP size determination.

\subsection{Errors in the non-linear fitting of EDX line-scan profiles}

Evaluation of possible errors in the fitting of SPP sizes from EDX data needs to be made before any quantitative results can be presented. The first possible error arises from the location of scanned lines over the same SPP in TEM sessions before and after irradiation. To minimise this error, perpendicular lines were carefully drawn across the centre of the particle, as shown in Figure 3. We estimate from analysis of the effect of deliberately misplaced line scans that this introduces to the particle size measurements an error of about $1 \%$. The second type of error comes from the assumption that SPPs are all ideal spheres. To minimise this problem, only SPPs clearly well separated in the initial images, circular in appearance and with diameters smaller than the measured sample thickness were used to increase the possibility that the SPPs are fully embedded in the TEM foil. The contrast of the SPPs in HAADF images is also a useful guide since for SPPs of the same apparent size a higher contrast with the surrounding matrix indicates that more of the SPP is embedded in the foil. The fitting quality to equation 1 is also helpful, and a minimum threshold of 0.9 is set for the $\mathrm{R}^{2}$ value of selected SPPs. Considering all these factors, we estimate that a 5\% error should be assumed for all the SPPs radii reported below.

\subsection{Obtaining compositional information from EDX line-scan profiles}

In addition to the use of non-linear curve fitting of EDX data to measure size changes, any redistribution of $\mathrm{Nb}$ atoms can also be investigated by comparing line-scan 
profiles before and after irradiation. Based on the work of Castaing [27], we assume that the TEM foil is thin enough so the ratio of intensities of the X-ray signals of two elements is proportional to the ratio of concentration of these two elements in the region analysed, so by comparing $\mathrm{Nb}$ signals in line-scan profiles before and after irradiation, any changes in $\mathrm{Nb}$ content can be measured.

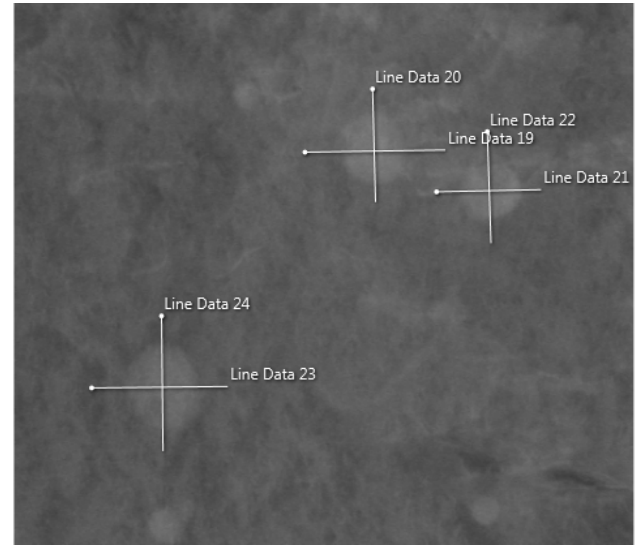

before

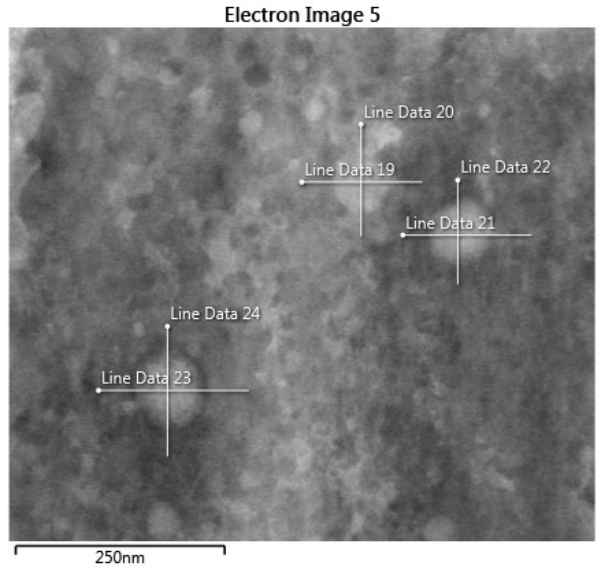

after

Figure 3 HAADF images showing the position of the EDX line-scans taken of the same SPPs before and after irradiation by $1 \mathrm{MeV} \mathrm{Kr}$ ions to $15 \mathrm{dpa}$ at $293 \mathrm{~K}$.

Direct comparison of $\mathrm{Nb}$ signals before and after irradiation requires careful normalisation. In a line-scan profile we have data from both the region containing the SPP and from the $\mathrm{Zr}$ matrix. The ratio between the integrated value of $\mathrm{Nb}$ signals in the SPP region and the average value of the $\mathrm{Zr}$ signal in the matrix was compared before and after irradiation. If the number of $\mathrm{Zr}$ atoms in the same region of the matrix is assumed to remain unchanged, any differences in instrumental settings can be corrected. However, the thickness of the TEM lamella might have been modified by sample sputtering during in-situ irradiation, and the extent of this sputtering depends on various factors including incident species and energy, the incidence angle of the beam and irradiation temperature [28]. The thickness of each sample can be tracked by EELS [29] before and after irradiation, but this measurement is not always easy especially when surface oxides are forming during irradiation. As a control, a separate sample was irradiated to $10 \mathrm{dpa}$ at room temperature at MIAMI2, sample A 
in Table 2. Using the EFTEM capability on the Hitachi-9500 TEM, the thickness of the foil was measured immediately before and after irradiation, with the sample remaining under vacuum in the same position in the microscope chamber. Zero loss mapping of the same region in the sample was used to compare the thickness of the TEM foil, and after 10 dpa no change in thickness was detected within experimental error $( \pm 10 \mathrm{~nm})$. Furthermore, SRIM simulations of $\mathrm{Zr}$ sputtering due to $350 \mathrm{keV} \mathrm{Kr}$ ions up to $10 \mathrm{dpa}$ indicate the sputtered thickness to be less than $2 \mathrm{~nm}$. We are thus confident that changes in sample thickness as a result of sputtering during our in-situ experiments can be considered to be negligible.

In order to study the redistribution of Nb in the TEM foils during in-situ ion implantation, depth profile measurements were performed with a Cameca NanoSIMS50 ion probe. A $16 \mathrm{keV}$ primary $\mathrm{Cs}^{+}$beam focussed to a nominal diameter of $60 \mathrm{~nm}$ was scanned over a measurement area of 3x3 $\mu \mathrm{m}$ on the TEM sample and ${ }^{93} \mathrm{Nb}^{-}$sputtered secondary ions collected in a double-focused mass spectrometer. 2D images (planes) with a dwell time of $1000 \mu$ s per pixel were generated sequentially. Collecting 400 planes results in a total sputter depth of $\sim 100 \mathrm{~nm}$, penetrating completely through the TEM sample, and allowing analysis of the chemistry of the back surface of the foil. This avoids the artefacts associated with the study of the front surface where steady-state sputtering conditions are not yet established and signal intensities show severe initial transients [30].

\section{Experimental results}

Bright field TEM images (Figure 4 a and c) show the morphology of SPPs primarily from diffraction contrast. The scattered black line features in Figure $4 \mathrm{c}$ are assumed to be a mixture of irradiation-induced dislocations and surface oxides formed during the irradiation session. The crystal structure of the $\beta$-Nb SPPs can be monitored by selected area diffraction, as shown in Figure 4. Using a selected area aperture diameter so that the SPP covers as much of the area as possible, the diffraction 
patterns contain reflections from both the $\alpha$-Zr matrix (connected by white dashed lines in Figure $4 \mathrm{~b}$ and $\mathrm{d}$ ) and the $\beta$-Nb SPPs (surrounded by white circles), and we can determine that all of these SPPs are incoherent with the matrix, in agreement with [31]. About $20 \beta-\mathrm{Nb}$ SPPs were tracked in each sample both before and after irradiation, and it is clear that the $\beta$-Nb SPPs retained the same crystal structure after irradiation to $15 \mathrm{dpa}$ at all four temperatures from $50 \mathrm{~K}$ to $873 \mathrm{~K}$.

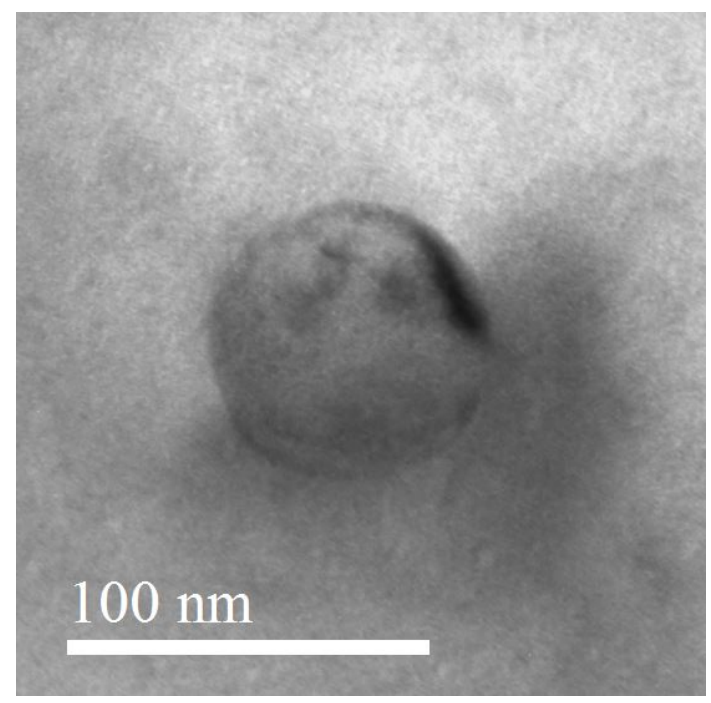

(a)

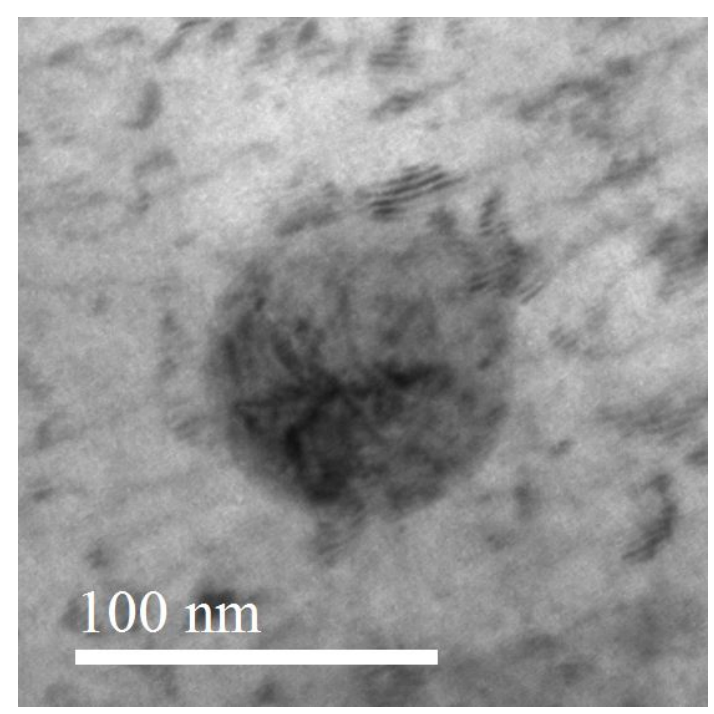

(c)

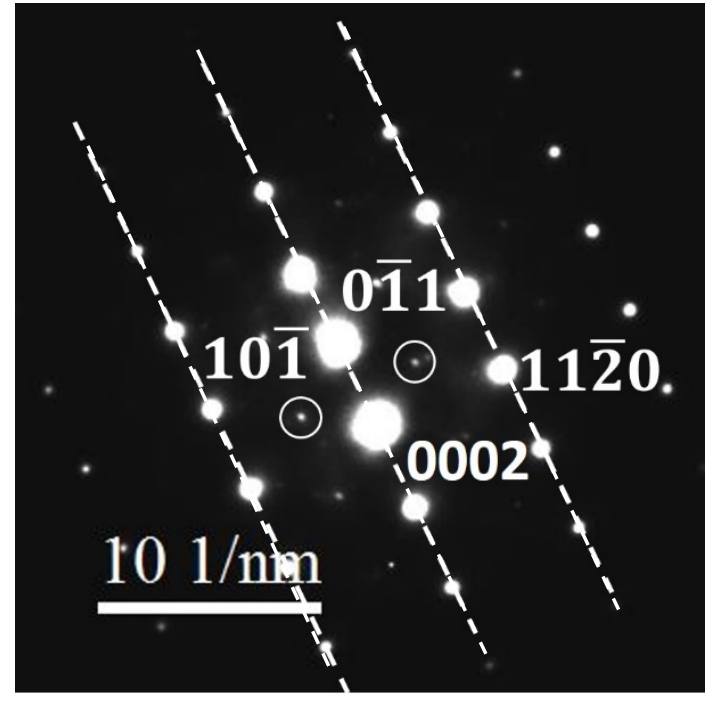

(b)

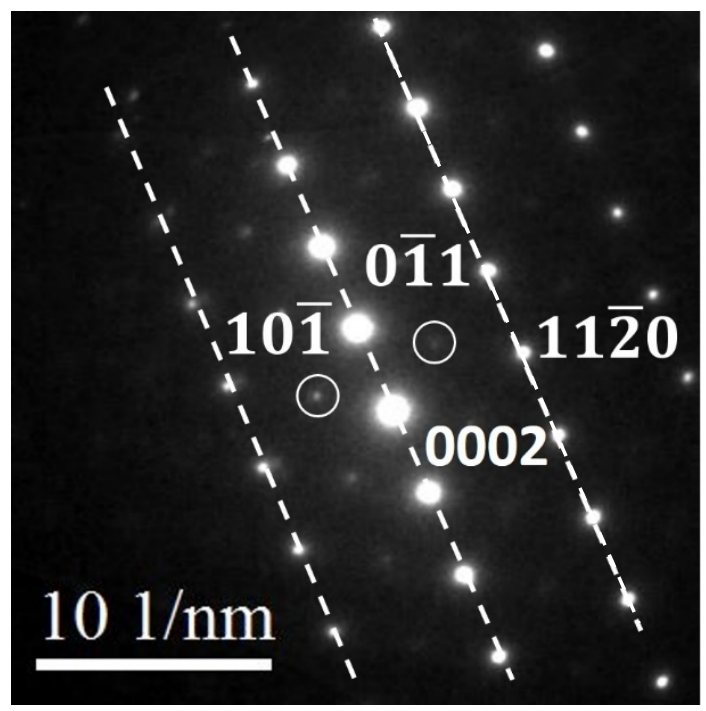

(d)

Figure 4 An example of monitoring a single $\beta$-Nb particle before and after irradiation by $1 \mathrm{MeV} \mathrm{Kr}$ ions at 293K. (a) BF image and (b) SADP at Odpa, (c) BF image and (d) SADP of the same particle after 15dpa. 
To measure any potential size changes, EDX line-scans were carried out on about 20 $\beta$-Nb SPPs in each sample following the method described above to obtain an average value of size changes at each temperature. The results of this analysis are shown in Figure 5, and the only temperature at which any size increase in the $\beta$-Nb SPPs can be detected outside the error bars is after irradiation at $623 \mathrm{~K}$.

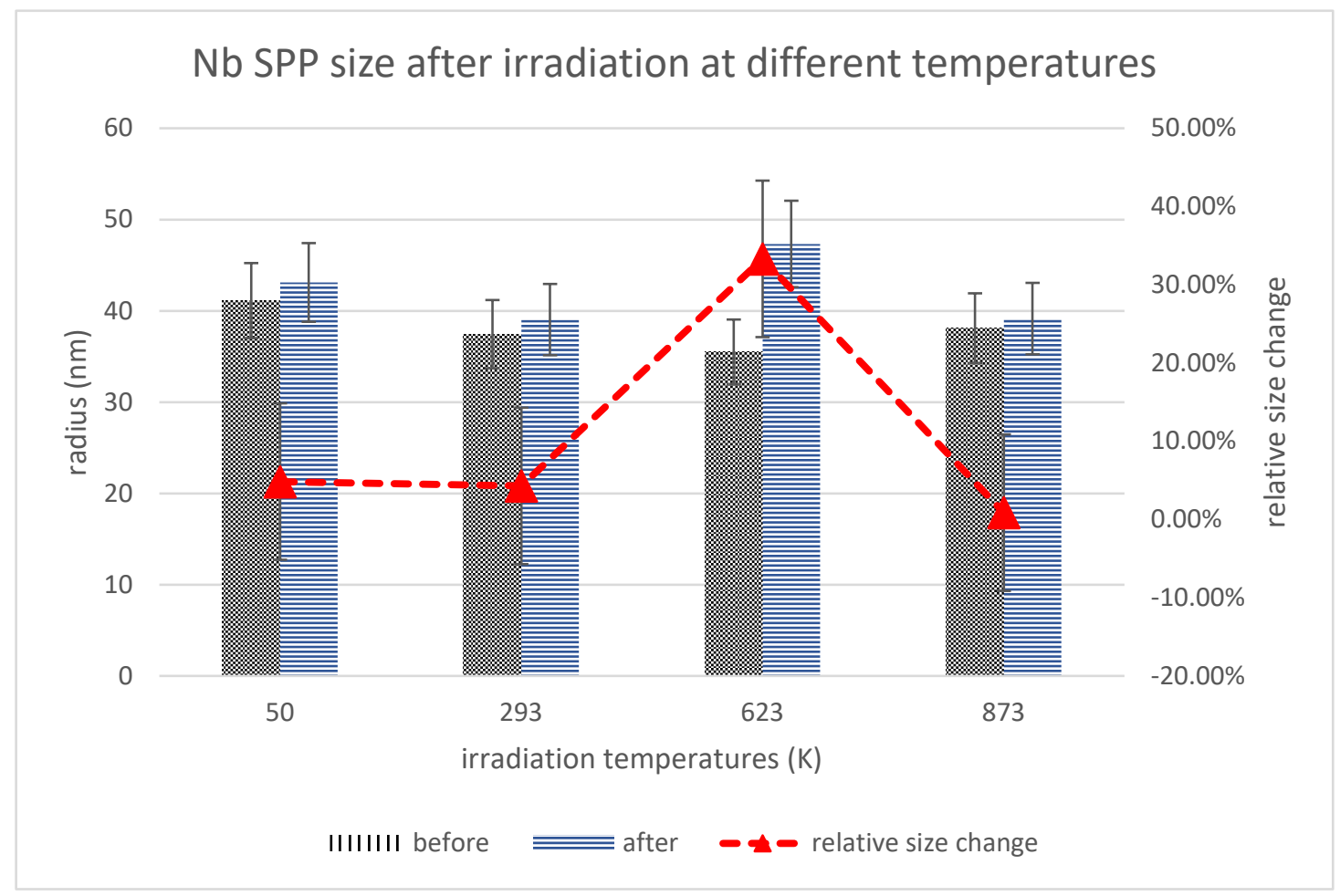

Figure 5 Averaged values of the size of $\beta$-NB SPPs before and after irradiation at 4 different temperatures, and the percentage size changes. The error bars of the average size of the SPPs represent the estimated errors of the size measurement as described in section 2.4, and those error bars of the relative size change are derived values from the calculation accordingly. It should be noted that the average size only stand for the particular SPPs investigated in this study, not the general average size of the SPPs in this material.

A typical set of line-scan profiles showing compositional changes in SPPs at different temperatures is shown in Figure 6. At low temperatures (293 K), a change of $\mathrm{Nb}$ concentration was only detected at the periphery of this SPP, as marked by the red dashed lines. In the intermediate temperature regime (623 K), a reduction of $\mathrm{Nb}$ concentration can be seen in the inner part of the SPP, with an increase of $\mathrm{Nb}$ 
concentration at the outer surface. At high temperature, the line-scan profiles show very little change even after very high irradiation levels. A detailed discussion of these observations is given in section 4.1.

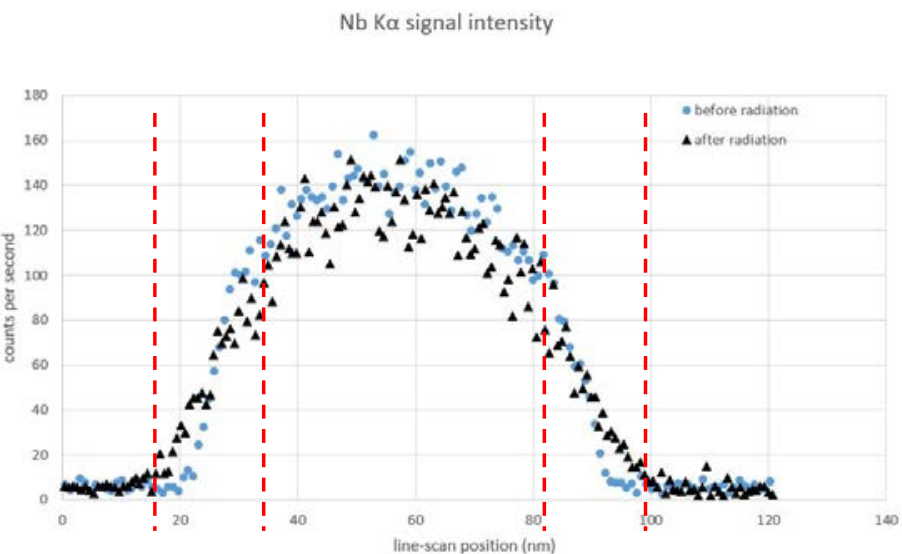

(a)

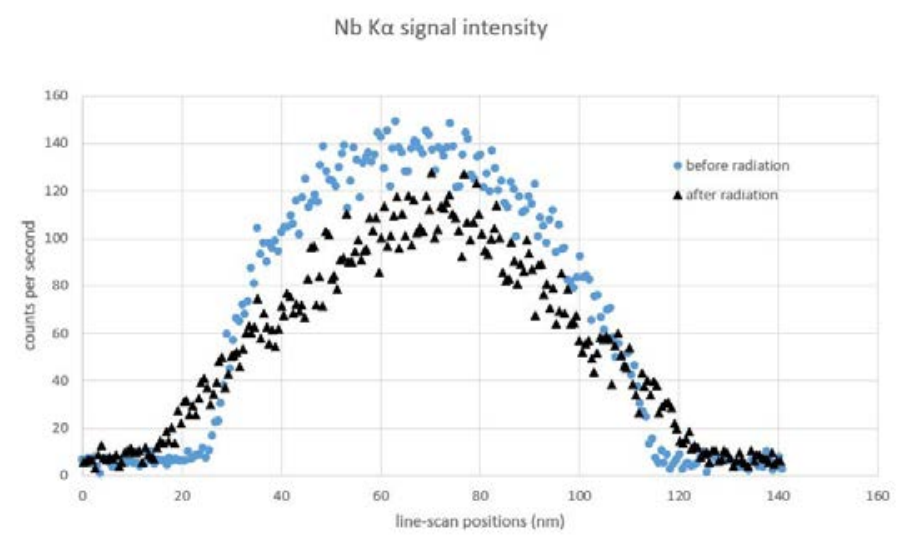

(b)

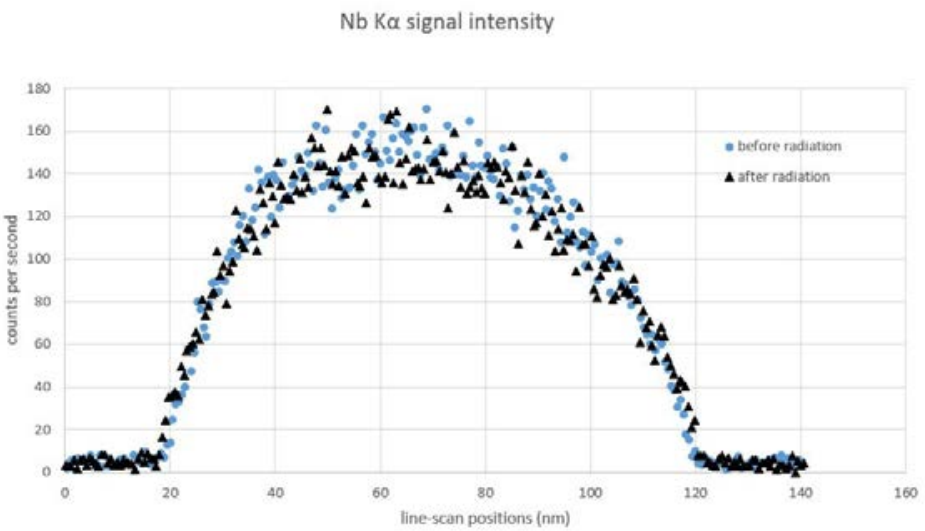

(c)

Figure 6 Typical EDX line-scan profiles of the Nb Ka signal for SPPs irradiated at (a) 293K, (b) 623K, (c) $873 \mathrm{~K}$. Compared to the cases at $293 \mathrm{~K}$ and $873 \mathrm{~K}$, a more obvious mixing region can be seen at the periphery of the SPP at $623 \mathrm{~K}$. 
A further set of samples (a-d) were irradiated to different damage levels at $623 \mathrm{~K}$ and again about $20 \beta$-Nb SPPs were characterised by EDX line-scans in each sample before and after radiation. These EDX line-scans can be divided into two categories; those measured parallel to the a direction (and so lying in the basal plane) and those along the c direction of the $\alpha$-Zr matrix. The size changes in each direction were calculated separately, and the results are shown in Figure 7. It is obvious that the measured increases in size along the c-direction are systematically larger than in the basal plane. This comparison not only is true for the average values, but for every individual SPP examined. Using the assumption discussed above that the thickness of the TEM foil does not change during irradiation, the absolute amount of $\mathrm{Nb}$ in each SPP (the sum of all the Nb counts in the SPP in the line-scan profiles) can be compared before and after irradiation. Our results show that within the errors discussed above, the Nb content remains unchanged after irradiation.

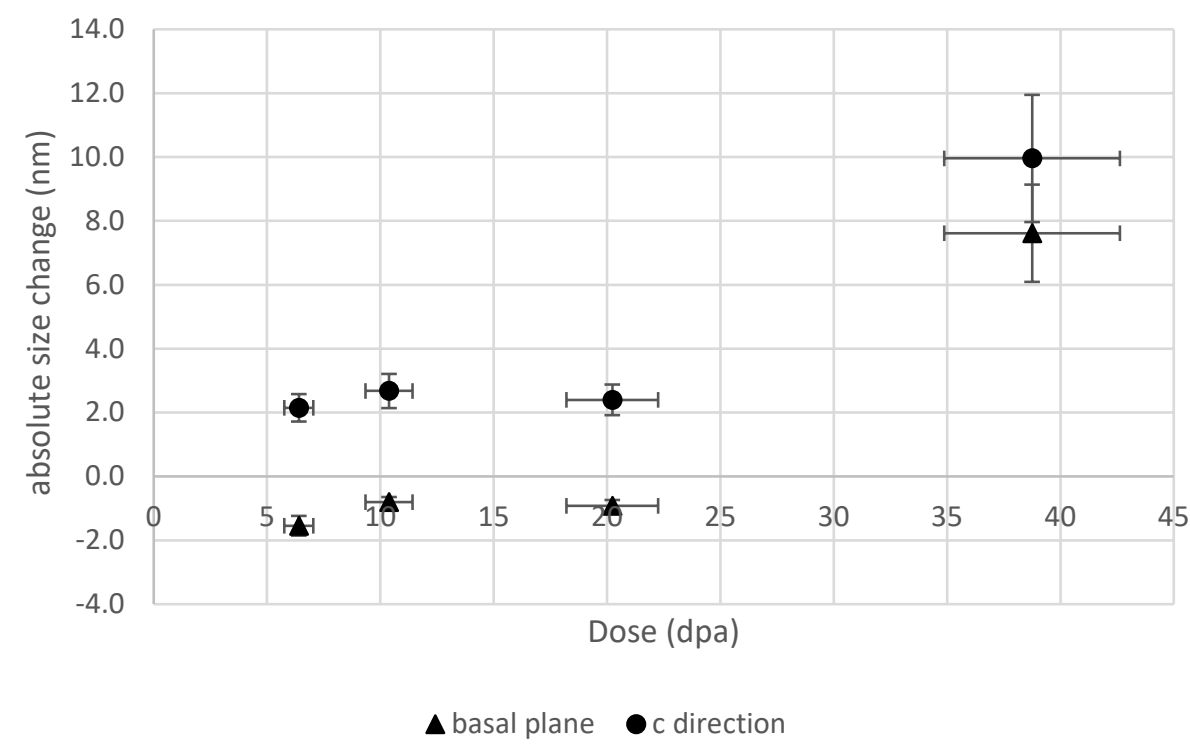

Figure 7 Average value of absolute size changes in $\beta$-NB SPPs measured along a and c directions in the Zr matrix after irradiation to different damage levels at $623 \mathrm{~K}$. The errors in $\mathrm{Y}$ axis come from the uncertainties in measurement and line-scan profile fitting, as discussed in section 2.4. The errors in $\mathrm{X}$ axis represent the uncertainties of the damage dose measurement during the in-situ irradiation session. An error of $10 \%$ relative to the dose is assumed. 
It is also worth mentioning that using the $[10 \overline{1} 0]$ or $[11 \overline{2} 0]$ zone axis for imaging and EDX line-scans has also allowed a careful search for the 'needle like' irradiationinduced $\mathrm{Nb}$ precipitates reported in neutron and proton irradiated $\mathrm{Zr}$-Nb alloys [19][32]. We have observed no precipitates of this kind in any of the samples examined in this study. A similar result was reported by Motta et al. for the in-situ irradiation of Zr-Nb and Zr model alloys [33]. The implications of this observation will be discussed in section 4.1 .

\section{Discussion}

There is an extensive discussion in the literature on radiation-induced changes to systems containing more than one phase, like the $\mathrm{Zr}-\mathrm{Nb}$ alloys we have studied here. It is commonly agreed that phase stability is affected by the redistribution of solute elements governed by competing mechanisms that can be divided into two categories [34]; irradiation-induced mixing that is primarily ballistic in nature, and diffusional processes where the kinetics are strongly temperature dependent. Which of these processes is dominant depends on the precise conditions of irradiation.

Ballistic mixing [35] is directly driven by displacement damage from primary and secondary knock-on events. Cascade damage will cause extensive mixing in regions such as the periphery of SPPs where the initial composition changes abruptly [36]. This kind of damage is commonly seen in heavy ion and neutron radiation where dense cascades are generated, and the kinetics of the process depends only on radiation-related parameters such as flux, the energy and mass of the incident particles [37], and is considered athermal.

At the same time, a dynamic equilibrium will be established between the creation of excess concentrations of point defects and defect clusters [35] and diffusional processes that can lead to their annihilation by direct recombination and absorption at sinks. At low temperatures and low initial sink densities, local recombination will be 
the dominant process for eliminating point defects, and the faster diffusion rate of interstitials will result in them moving not only to annihilate at the slower moving vacancies but also to other sinks like the free surfaces of a TEM sample. As irradiation continues, the interstitial concentration will thus decrease with respect to the vacancies, and radiation enhanced diffusion (RED) via this excess vacancy concentration will gradually become the dominant transport process. At higher temperatures where the diffusion rates are faster [32], coupling between the fluxes of radiation-induced defects and solute and impurity elements to sinks such as surfaces, grain boundaries or interphase boundaries will result in radiation induced segregation (RIS) [38]. In this study, the $\beta$-Nb particles themselves will act as important sinks of solute $\mathrm{Nb}$ atoms, but the sink strength will depend on temperature. The equilibrium concentration of $\mathrm{Nb}$ in the $\beta-\mathrm{Nb}$ phase has a minimum value of about $90 \mathrm{wt} \%$ at around $890 \mathrm{~K}$ and increases rapidly at lower temperatures [39]. However, the initial $\mathrm{Nb}$ concentration in the $\beta$-Nb SPPs in both alloys used in this study has been directly measured by Atom Probe Tomography to be about $80 \mathrm{wt} \%$ [40], i.e. they are not at their equilibrium concentration after alloy manufacture. As a result, we should expect in our experiments the primary flux of $\mathrm{Nb}$ atoms in the matrix near a SPP always to be towards the $\beta-\mathrm{Nb}$ SPPs.

At low temperatures RIS will be limited by the low defect mobility and high recombination rate of vacancies and interstitials, but at higher temperatures the increased thermal vacancy concentration leads to enhanced recombination and faster back diffusion of species displaced from the equilibrium phases, limiting the effect of RIS to sinks other than the existing SPPs. At intermediate temperatures, the increased participation of solute atoms in defect fluxes other than directly back into the SPPs can result in more segregation to other sinks. This segregation can also drive the matrix concentration above the solubility limit, inducing additional precipitation of a second phase (like the nano-precipitates mentioned above [18, 32]). 
lamella are so thin that the two large free surfaces must be expected to act as preferred sinks for defects, and may reduce matrix supersaturation of $\mathrm{Nb}$ and limit backdiffusion to the SPP/matrix interfaces. Evidence supporting this mechanism comes from two experimental observations; (i) that no radiation-induced $\mathrm{Nb}$ precipitates have been created in the matrix in any of the samples studied above, and (ii) that $\mathrm{Nb}$ segregation to the free surfaces has been directly measured by SIMS analysis after insitu damage, but only at $623 \mathrm{~K}$ as shown in Figure 8. Matrix nano-precipitation in bulk samples [19][32] is a result of supersaturated solute atoms segregating into defect clusters in the matrix, but this supersaturation may have been eliminated in our samples by the proximity of the free surfaces [33]. The SIMS result is also direct evidence that this surface segregation process is an important contribution to the overall balance of solute redistribution at the intermediate temperature of $623 \mathrm{~K}$, but at neither $293 \mathrm{~K}$ nor at $873 \mathrm{~K}$.

Modelling of the stability of precipitates under radiation damage [41][37][42] by considering the balance between radiation mixing driven dissolution of SPPs and back-diffusion of solute atoms to their thermodynamically preferred location in the SPPs. This work suggests that SPPs should generally be unstable under irradiation at low temperatures because the rate of diffusion is too slow to compensate for the damage from radiation mixing. The low-temperature limit for stability was predicted by Turkin et al. [37] to be around $900 \mathrm{~K}$ for incoherent SPPs (like the $\beta$-Nb precipitates studied here) irradiated at $10^{-4} \mathrm{dpa} / \mathrm{s}$, and to lie at even higher temperatures for higher fluxes. However, this does not match the experimental observations made on $\beta$-Nb SPPs under neutron [19] and proton [32] irradiation in the intermediate temperature range ( $\sim 00 \mathrm{~K}$ ) where $\beta$-Nb SPPs always showed good stability to high damage levels, or our results presented above where $\beta$-Nb shows exceptional crystallographic stability under heavy ion radiation at $10^{-3} \mathrm{dpa} / \mathrm{s}$ up to 20 dpa at 50 K, 293 K, 873 K, and some modest spreading in the Nb profile only at $623 \mathrm{~K}$. 


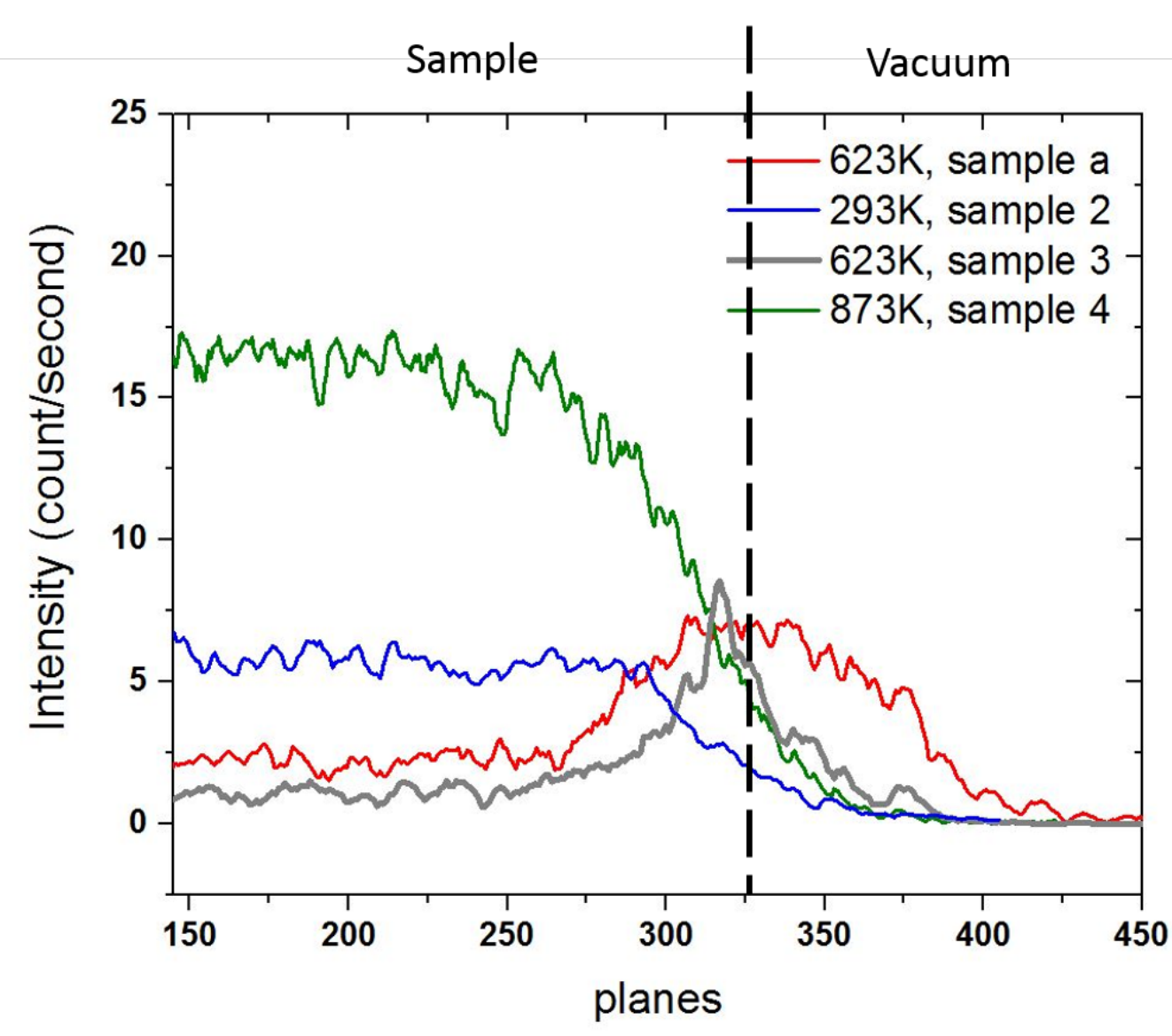

Figure 8. NanoSIMS depth profiles for Nb in the lower half of TEM thin foils irradiated to 20 dpa at 293, 623 and $873 \mathrm{~K}$. The black dash line indicates the rough position of the sample surface. The bottom surface of the foils shows $\mathrm{Nb}$ segregation only in the 2 samples irradiated at $623 \mathrm{~K}$, and a reduction of counts in the metal bulk.

In the experiments reported here, we suppose that at low temperatures (50 K and 293 $\mathrm{K}$ ) the observed change of $\mathrm{Nb}$ concentration between the SPP and the matrix (Figure 6a) is limited by the low mobility of radiation-induced defects and the high rate of recombination of vacancies and interstitials locally. At higher temperatures, the $\mathrm{Nb}$ concentration in the matrix is determined by radiation-enhanced diffusion of solute $\mathrm{Nb}$ atoms towards sinks, which in our samples include SPPs, the large free surfaces of the TEM lamella and grain boundaries. At an intermediate temperature (623 K), the solute atoms segregate preferentially to the large free surfaces as shown in Figure 8, and the $\mathrm{Nb}$ concentration in the matrix decreases. In the high temperature regime (873 $\mathrm{K})$, the diffusion of solute $\mathrm{Nb}$ atoms towards free surfaces is suppressed by the well- 
known reduction in the efficiency of equilibrium segregation mechanisms at higher temperatures captured in the McLean Isotherm [43], so that local back diffusion towards the $\beta$-Nb SPPs becomes the dominant mechanism for $\mathrm{Nb}$ redistribution.

Combining these factors together, a simple model describing the behaviour of $\beta-\mathrm{Nb}$ SPPs under irradiation in this study can be suggested. The incident $\mathrm{Kr}$ ions create cascades that form a mixing zone at the SPP/matrix interface seen in the broadened EDX Nb profiles, Figures 6(b) and 7. This growth process is opposed by diffusion of $\mathrm{Nb}$ atoms back to the damaged SPP, but the driving force for this back diffusion depends on the irradiation temperature because of the strong variations in the equilibrium composition of both matrix and SPP in the phase diagram. Radiation mixing at low temperatures ( $50 \mathrm{~K}$ and $293 \mathrm{~K}$ ) leaves a narrow mixing zone at the periphery of the SPPs, Figure 6(a). At high temperatures (823 K), surface segregation is suppressed, Figure 8, and $\mathrm{Nb}$ diffusion in the $\mathrm{Zr}$ matrix is so fast that all the radiation mixing is recovered by back diffusion, Figure 6(c). In the intermediate temperature regime (623 K), the balance between back diffusion, diffusional fluxes to other strong sinks like free surfaces and changes in the equilibrium composition of the $\beta$-Nb SPPs combine to give apparent growth of the SPPs as measured by EDX line profiles. At this temperature, the increase in SPP size is accompanied by a reduction of Nb concentration within the SPPs, Figure 6(b), but we do not believe that this is evidence for the onset of dissolution because the SPPs retain their bcc structure even after $40 \mathrm{dpa}$ and the amount of $\mathrm{Nb}$ redistributed from the SPP to the surrounding matrix is very limited (by comparing the total $\mathrm{Nb}$ amounts within the SPPs before and after irradiation) . This agrees with the concept of ballistic introduction of $\mathrm{Zr}$ atoms into the SPPs $[18,20]$.

Compared to the mechanisms suggested by previous researchers, the model proposed here underlines the important role of anisotropic local diffusion of $\mathrm{Nb}$ in the $\mathrm{Zr}$ matrix in determining the behaviour of $\beta$-Nb SPPs under irradiation. The known anisotropy of diffusion coefficients for $\mathrm{Nb}$ in the basal plane and c direction in the $\alpha$-Zr matrix 
[44] can lead to the changes in shape of the SPPs reported in Figure 7. The preferential expansion along the c direction is due to slower back diffusion of radiation-displaced $\mathrm{Nb}$ atoms towards the SPPs. The contraction of the SPPs along the basal plane at 62 3K up to 20 dpa but then growth at 40 dpa suggests a change in diffusion behaviour that might be related to the formation of lattice defects in the matrix. For instance, Harte et al. [45] showed in proton-irradiated Zircaloy2 samples that segregation of solute elements like $\mathrm{Fe}, \mathrm{Ni}$ and $\mathrm{Cr}$ to a-loops enhances the dissolution of SPPs. However, we do not observe similar segregation behaviour in our study, and the onset of formation of c-loops cannot account for this change in SPP dimensions since, as shown in Figure 2, c-loops appear at 5 dpa and are present in large concentrations at $10 \mathrm{dpa}$, well before the observed onset of SPP growth at 20 dpa. Some future simulation work might be helpful to explain this phenomenon.

Now we consider how this model can help understand the behaviour of $\beta$-Nb SPPs in the reactor core environment, where the primary differences compared to the in-situ heavy ion irradiation used here are the irradiating species and flux and the operational temperature. Fast neutrons will generate larger cascades than heavy ion damage [34], increasing the size of mixing regions at the outer surface of the SPPs, but the typical dose rate of in-service neutron radiation (about $10^{-7} \mathrm{dpa} / \mathrm{s}$ ) is so much lower than the high heavy ion flux used here that there will be much longer recovery times between the generation of individual cascades at the same location. The operating temperatures in PWR reactors are around $600 \mathrm{~K}$ [1], similar to the intermediate temperature used in this study, but back diffusion of $\mathrm{Nb}$ atoms from the matrix towards the SPPs will be much faster at the highest temperature we have used of $823 \mathrm{~K}$. The absence of free surfaces (the typical grain size is several microns in fuel cladding alloys [19][18] so grain boundary sinks will typically be much further away than the surfaces of the TEM sample) will encourage radiation-enhanced segregation of displaced $\mathrm{Nb}$ atoms from the matrix to SPPs, and further protect the SPPs from dissolution.

With all these factors considered, we suggest that the results from in-situ irradiation at 
$623 \mathrm{~K}$ are representative of the changes to $\beta-\mathrm{Nb}$ SPPs under neutron irradiation. The results of Shishov and others on radiation damage in Russian Zr-Nb alloys have shown size increases from $50 \mathrm{~nm}$ to $80 \mathrm{~nm}$ after $20 \mathrm{dpa}$ [21] and Nb content reduction [21][46] under neutron radiation at $\sim 600 \mathrm{~K}$. Studies of the in core neutron radiation damage at about $600 \mathrm{~K}$ of the French $\mathrm{M} 5^{\mathrm{TM}}$ alloy also show a size increase of SPPs from $35 \mathrm{~nm}$ to $50 \mathrm{~nm}$ after $5 \mathrm{dpa}$ and a reduction of $\mathrm{Nb}$ content from about $80 \mathrm{wt} \%$ to $55 \mathrm{wt} \%$. These observations are very similar to our results at $623 \mathrm{~K}$, although we have also shown that the SPPs grow more in the c-direction. Yet there are also some significant differences. The SPP growth reported by Doriot et al. [19] increases with damage up to 5 dpa, then stabilises, while in Figure 7 we show that the SPPs keep growing to higher damage levels. During low-fluence neutron irradiation, we suppose this may be due to $\mathrm{Nb}$ diffusion to other radiation-induced defects such as c-loops, or to form nano-precipitates, that will reduce the matrix $\mathrm{Nb}$ supersaturation and diffusion towards the SPPs. This effect is largely suppressed in this study due to the presence of the large free surface acting initially as strong sinks. Once these surface sinks are saturated, the equilibrium of the Nb between the SPPs and matrix then takes longer to reach in the in-situ heavy ion radiation at $623 \mathrm{~K}$ than that in neutron radiation under service conditions.

It is also interesting that the SIMS data in Figure 8 suggests that there is a measurable reduction of $\mathrm{Nb}$ content in the matrix only at $623 \mathrm{~K}$, a factor that has been suggested to be beneficial for the corrosion resistance of $\mathrm{Zr}-\mathrm{Nb}$ alloys [15].

\section{Conclusions}

We have shown that in-situ heavy ion irradiation, combined with careful EDX analysis, is a powerful tool to understand how second phase particles in nuclear zirconium alloys respond to radiation damage, especially if the same SPPs are characterised before and after irradiation. The unique strength of this approach, and ways to reduce possible errors, have been discussed, and the new observation of 
differential growth in the basal plane and along the c-direction at high dpa levels. A model describing the mechanisms governing the response of $\beta$-Nb SPPs to radiation damage at different temperatures has been suggested to explain the exceptional resistance of small particles of this phase even to very high damage levels. The application of this model to in-reactor neutron irradiation damage has also been discussed, including why irradiation does not encourage significant Nb transfer from SPPs to solid solution in the matrix. When combined with the reduction of $\mathrm{Nb}$ concentration in the $\mathrm{Zr}$ matrix by formation of $\mathrm{Nb}$ nano-precipitates under in-reactor conditions, this stability of the $\beta$-Nb SPPs is very important in contributing to the exceptional corrosion resistance of these alloys.

\section{Acknowledgements}

The authors are grateful to Dr. Meimei Li, Dr. Mark Kirk, Mr. Ed Ryan and Mr. Pete Baldo for their kind help in designing and carrying out the in-situ irradiation experiment at the IVEM facility, Argonne Laboratory. The authors are grateful to Prof. Steve Donnelly, Dr. Jonathan Hinks, Dr. Graeme Greaves for their kind help in designing and carrying out the in-situ irradiation experiment at the MIAMI 2 facility, University of Huddersfield. The authors acknowledge the contribution made to this work by their collaborators from Westinghouse and the MUZIC project providing zirconium alloy samples. EPSRC grants (EP/K040375/1 and EP/N010868/1) are acknowledged for funding the 'South of England Analytical Electron Microscope' and the Zeiss NVision FIB/SEM used in this research.

\section{References}

[1] L. Hallstadius, S. Johnson, E. Lahoda, Cladding for high performance fuel, Prog. Nucl. Energy. 57 (2012) 71-76. doi:10.1016/j.pnucene.2011.10.008.

[2] A.T. Motta, A. Couet, R.J. Comstock, Corrosion of Zirconium Alloys Used for Nuclear Fuel Cladding, Annu. Rev. Mater. Res. 45 (2015) 311-343. doi:10.1146/annurev-matsci-070214-020951.

[3] E. Hillner, D.. Franklin, J.. Smee, Long-term corrosion of Zircaloy before and 
after irradiation, J. Nucl. Mater. 278 (2000) 334-345. doi:10.1016/S00223115(99)00230-5.

[4] A.T. Motta, M.J. Gomes da Silva, A. Yilmazbayhan, R.J. Comstock, Z. Cai, B. Lai, Microstructural Characterization of Oxides Formed on Model Zr Alloys Using Synchrotron Radiation, in: Zircon. Nucl. Ind. 15th Int. Symp., ASTM International, 100 Barr Harbor Drive, PO Box C700, West Conshohocken, PA 19428-2959, 2009: pp. 486-486-21. doi:10.1520/STP48151S.

[5] A. Yilmazbayhan, A.T. Motta, R.J. Comstock, G.P. Sabol, B. Lai, Z. Cai, Structure of zirconium alloy oxides formed in pure water studied with synchrotron radiation and optical microscopy: relation to corrosion rate, J. Nucl. Mater. 324 (2004) 6-22. doi:10.1016/J.JNUCMAT.2003.08.038.

[6] T.R. Allen, R.J.M. Konings, A.T. Motta, Corrosion of Zirconium Alloys, in: R.J.M. Konings (Ed.), Compr. Nucl. Mater., Elsevier Ltd, Amsterdam, 2012: pp. 49-68. doi:10.1016/B978-0-08-056033-5.00063-X.

[7] A. Garner, J. Hu, A. Harte, P. Frankel, C. Grovenor, S. Lozano-Perez, M. Preuss, The effect of Sn concentration on oxide texture and microstructure formation in zirconium alloys, Acta Mater. 99 (2015) 259-272. doi:10.1016/j.actamat.2015.08.005.

[8] A. Couet, A. Motta, R. Comstock, Effect of alloying elements on hydrogen pickup in zirconium alloys, Zircon. Nucl. Ind. 17th. (2015). http://www.astm.org/DIGITAL_LIBRARY/STP/PAGES/STP154320120215.ht m (accessed April 9, 2017).

[9] B.D.C. Bell, S.T. Murphy, R.W. Grimes, M.R. Wenman, The effect of Nb on the corrosion and hydrogen pick-up of Zr alloys, Acta Mater. 132 (2017) 425431. doi:10.1016/j.actamat.2017.04.063.

[10] P. Tejland, H.-O. Andrén, G. Sundell, M. Thuvander, B. Josefsson, L. Hallstadius, M. Ivermark, M. Dahlbäck, Oxidation Mechanism in Zircaloy-2The Effect of SPP Size Distribution, in: Zircon. Nucl. Ind. 17th Vol., ASTM International, 100 Barr Harbor Drive, PO Box C700, West Conshohocken, PA 19428-2959, 2015: pp. 373-403. doi:10.1520/STP154320130052. 
[11] B.-C. Cheng, R. Kruger, R. Adamson, R. Adamson, Corrosion Behavior of Irradiated Zircaloy, in: Zircon. Nucl. Ind. Tenth Int. Symp., ASTM International, 100 Barr Harbor Drive, PO Box C700, West Conshohocken, PA 19428-2959, 1994: pp. 400-400-19. doi:10.1520/STP15200S.

[12] G. Sabol, R. Comstock, R. Weiner, P. Larouere, R. Stanutz, In-Reactor Corrosion Performance of ZIRLO ${ }^{\mathrm{TM}}$ and Zircaloy-4, in: Zircon. Nucl. Ind. Tenth Int. Symp., ASTM International, 100 Barr Harbor Drive, PO Box C700, West Conshohocken, PA 19428-2959, 1994: pp. 724-724-21. doi:10.1520/STP15217S.

[13] M. Bojinov, L. Hansson-Lyyra, P. Kinnunen, T. Saario, P. Sirkiä, In-Situ Studies of the Oxide Film Properties on BWR Fuel Cladding Materials, in: Zircon. Nucl. Ind. Fourteenth Int. Symp., ASTM International, 100 Barr Harbor Drive, PO Box C700, West Conshohocken, PA 19428-2959, 2005: pp. 367367-19. doi:10.1520/STP37516S.

[14] F. Garzarolli, W. Goll, A. Seibold, I. Ray, Effect of In-PWR Irradiation on Size, Structure, and Composition of Intermetallic Precipitates of Zr Alloys, in: Zircon. Nucl. Ind. Elev. Int. Symp., ASTM International, 100 Barr Harbor Drive, PO Box C700, West Conshohocken, PA 19428-2959, 1996: pp. 541541-16. doi:10.1520/STP16189S.

[15] A. Couet, A.T. Motta, A. Ambard, The coupled current charge compensation model for zirconium alloy fuel cladding oxidation: I. Parabolic oxidation of zirconium alloys, Corros. Sci. 100 (2015) 73-84. doi:10.1016/j.corsci.2015.07.003.

[16] A. Couet, A.T. Motta, B. de Gabory, Z. Cai, Microbeam X-ray Absorption Near-Edge Spectroscopy study of the oxidation of Fe and $\mathrm{Nb}$ in zirconium alloy oxide layers, J. Nucl. Mater. 452 (2014) 614-627. doi:10.1016/j.jnucmat.2014.05.047.

[17] B. Cox, F. Garazarolli, P. Rudling, Corrosion of Zr-Nb Alloys ZIRAT-9 Special Topic on Corrosion of Zr-Nb Alloys, 2004.

[18] G.P. Kobylyansky, A.E. Novoselov, A. V. Obukhov, Z.E. Ostrovsky, V.N. 
Shishov, M.M. Peregud, V.A. Markelov, P. Barberis, S.W. Dean, Radiation Damage of E635 Alloy Under High Dose Irradiation in the VVER-1000 and BOR-60 Reactors, J. ASTM Int. 8 (2011) 102941. doi:10.1520/JAI102941.

[19] S. Doriot, B. Verhaeghe, J.-L. Béchade, D. Menut, D. Gilbon, J.-P. Mardon, J.M. Cloué, A. Miquet, L. Legras, Microstructural Evolution of M5 TM Alloy Irradiated in PWRs up to High Fluences-Comparison With Other Zr-Based Alloys, in: Zircon. Nucl. Ind. 17th Vol., ASTM International, 100 Barr Harbor Drive, PO Box C700, West Conshohocken, PA 19428-2959, 2015: pp. 759799. doi:10.1520/STP154320120179.

[20] V. Shishov, M. Peregud, A. Nikulina, Y. Pimenov, G. Kobylyansky, A. Novoselov, Z. Ostrovsky, A. Obukhov, Influence of Structure-Phase State of Nb Containing Zr Alloys on Irradiation-Induced Growth, in: J. ASTM Int., ASTM International, 2005: p. 12431. doi:10.1520/JAI12431.

[21] V. Shishov, M. Peregud, A. Nikulina, P. Shebaldov, A. Tselischev, A. Novoselov, G. Kobylyansky, Z. Ostrovsky, V. Shamardin, Influence of Zirconium Alloy Chemical Composition on Microstructure Formation and Irradiation Induced Growth, in: Zircon. Nucl. Ind. Thirteen. Int. Symp., ASTM International, 100 Barr Harbor Drive, PO Box C700, West Conshohocken, PA 19428-2959, 2002: pp. 758-758-22. doi:10.1520/STP11415S.

[22] V.N. Shishov, P. Barberis, S.W. Dean, The evolution of microstructure and deformation stability in $\mathrm{Zr}-\mathrm{Nb}-(\mathrm{Sn}, \mathrm{Fe})$ alloys under neutron irradiation, J. ASTM Int. 7 (2010) 103005. doi:10.1520/JAI103005.

[23] S. Lozano-Perez, A guide on FIB preparation of samples containing stress corrosion crack tips for TEM and atom-probe analysis, Micron. 39 (2008) 320328. doi:10.1016/J.MICRON.2007.12.003.

[24] R.M. Langford, A.K. Petford-Long, Preparation of transmission electron microscopy cross-section specimens using focused ion beam milling, J. Vac. Sci. Technol. A Vacuum, Surfaces, Film. 19 (2001) 2186-2193. doi:10.1116/1.1378072.

[25] R.F. Egerton, Electron energy-loss spectroscopy in the electron microscope, 
Springer, 2011.

[26] J. Ziegler, The Kinchin-Pease Model for Vacancy Production, in: SRIM Stopping Range Ions Matter, 15th ed., Lulu, 2015.

http://www.lulu.com/shop/james-ziegler/srim-the-stopping-and-range-of-ionsin-matter/hardcover/product-22155781.html (accessed October 20, 2018).

[27] CASTAING, R., Application of electron probes to local chemical and crystallographic analysis, 1951. https://ci.nii.ac.jp/naid/10017599260/.

[28] J.A. Hinks, Transmission electron microscopy with in situ ion irradiation, J. Mater. Res. 30 (2015) 1214-1221. doi:10.1557/jmr.2014.384.

[29] K. Iakoubovskii, K. Mitsuishi, Y. Nakayama, K. Furuya, Thickness measurements with electron energy loss spectroscopy, Microsc. Res. Tech. 71 (2008) 626-631. doi:10.1002/jemt.20597.

[30] K.L. Moore, M. Schröder, C.R.M. Grovenor, Imaging Secondary Ion Mass Spectroscopy, in: Handb. Nanoscopy, Wiley-VCH Verlag GmbH \& Co. KGaA, Weinheim, Germany, 2012: pp. 709-744. doi:10.1002/9783527641864.ch21.

[31] G. Yuan, L. Zhang, Q. Yue, H. Gu, G. Li, J. Shen, Microstructural characteristics of $\beta$ precipitates in Zr-1Nb alloy, Mater. Chem. Phys. 165 (2015) 87-90. doi:10.1016/J.MATCHEMPHYS.2015.08.058.

[32] E. Francis, R.P. Babu, A. Harte, T.L. Martin, P. Frankel, D. Jädernäs, J. Romero, L. Hallstadius, P.A.J. Bagot, M.P. Moody, M. Preuss, Effect of Nb and Fe on damage evolution in a Zr-alloy during proton and neutron irradiation, Acta Mater. 165 (2019) 603-614. doi:10.1016/J.ACTAMAT.2018.12.021.

[33] A.T. Motta, J.A. Faldowski, L.M. Howe, P.R. Okamoto, In situ studies of phase transformations in zirconium alloys and compounds under irradiation, in: American Society for Testing and Materials, 1996: pp. 557-579. https://www.scopus.com/record/display.uri?eid=2-s2.00030284964\&origin=inward\&txGid=02d034c9db6ffab9d4a8fb651ba49755 (accessed July 31, 2017).

[34] G.S. Was, Fundamentals of radiation materials science: metals and alloys, Springer Science \& Business Media, 2007. 
[35] A.T. Motta, C. Lemaignan, A ballistic mixing model for the amorphization of precipitates in Zircaloy under neutron irradiation, J. Nucl. Mater. 195 (1992) 277-285. doi:10.1016/0022-3115(92)90519-Q.

[36] K.C. Russell, Phase instability under cascade damage irradiation, J. Nucl. Mater. 206 (1993) 129-138. doi:10.1016/0022-3115(93)90120-N.

[37] A.A. Turkin, A. V. Buts, A.S. Bakai, Construction of radiation-modified phase diagrams under cascade-producing irradiation: application to $\mathrm{Zr}-\mathrm{Nb}$ alloy, J. Nucl. Mater. 305 (2002) 134-152. doi:10.1016/S0022-3115(02)01027-9.

[38] G.S. Was, P.L. Andresen, Radiation damage to structural alloys in nuclear power plants: mechanisms and remediation, in: Struct. Alloy. Power Plants, Woodhead Publishing, 2014: pp. 355-420. doi:10.1533/9780857097552.2.355.

[39] J.P. Abriata, J.C. Bolcich, The Nb-Zr (Niobium-Zirconium) system, J. Phase Equilibria. 3 (1982) 34-44. doi:10.1007/BF02873409.

[40] B. Setiadinata, Corrosion and Hydrogen Pickup Mechanisms of Zirconium Alloys, University of Oxford, 2016.

[41] R.S. Nelson, J.A. Hudson, D.J. Mazey, The stability of precipitates in an irradiation environment, J. Nucl. Mater. 44 (1972) 318-330. doi:10.1016/00223115(72)90043-8.

[42] P. Wilkes, Phase stability under irradiation - a review of theory and experiment, J. Nucl. Mater. 83 (1979) 166-175. doi:10.1016/00223115(79)90602-0.

[43] McLean Donald, Grain boundaries in metals, Oxford: Clarendon Press, Oxford, 1957.

https://books.google.co.uk/books/about/Grain_boundaries_in_metals.html?id=f khRAAAAMAAJ\&redir_esc=y.

[44] V.P. Ramunni, A.M.F. Rivas, Diffusion calculations with two atomic models in h.c.p Zr-Nb diluted alloys, Mater. Chem. Phys. 197 (2017) 163-180. doi:10.1016/J.MATCHEMPHYS.2017.05.022.

[45] A. Harte, D. Jädernäs, M. Topping, P. Frankel, C.P.P. Race, J. Romero, L. Hallstadius, E.C.C. Darby, M. Preuss, The effect of matrix chemistry on 
dislocation evolution in an irradiated Zr alloy, Acta Mater. 130 (2017) 69-82. doi:10.1016/j.actamat.2017.03.024.

[46] V.N. Shishov, M.M. Peregud, A. V. Nikulina, V.F. Kon’Kov, V. V. Novikov, V.A. Markelov, T.N. Khokhunova, G.O. Kobylyansky, A.E. Novoselov, Z.E. Ostrovsky, A. V. Obukhov, Structure-phase state, corrosion and irradiation properties of Zr-Nb-Fe-Sn system Alloys, J. ASTM Int. 5 (2008) 724-743. doi:10.1520/JAI101127. 